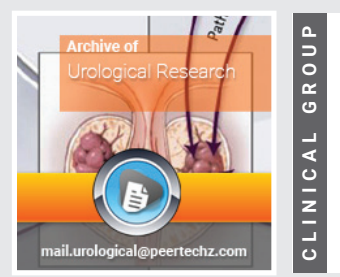

\section{Immediate Post-Operative} Course Following Open and Laparoscopic Orchiopexy of Abdominal Testes: Is There A Difference?

\author{
Kristina D Suson* and Yegappan Lakshmanan*
}

Children's Hospital of Michigan, 3901 Beaubien Detroit, MI 48201, USA
Received: 30 January, 2020

Accepted: 14 April, 2020

Published: 15 April, 2020

*Corresponding author: Kristina D Suson, Children's Hospital of Michigan, Detroit, MI 48201, USA, Tel: 313745-5588; Fax: 313-993-8738;

E-mail:kdsuson@gmail.com

Keywords: Cryptorchidism; Orchiopexy; Laparoscopy https://www. peertechz.com

Check for updates

\begin{abstract}
Purpose: Laparoscopic and open approaches are considered equivalent surgical options for the management of abdominal undescended testes, the choice of which is dependent upon surgeon experience and preference. We questioned whether immediate post-operative complications were equivalent.

Methods: The American College of Surgeons National Surgical Quality Improvement Program data file was queried for laparoscopic and open orchiopexies of abdominal testes $(54650,54692)$ from 2012-2014. Data points included: age, ASA class, type of surgeon, length of stay, operative time, complications, immediate reoperation, and readmission. Statistical analyses included Student's t-test and chi-square.

Results: A total of 1039 laparoscopic and 489 open abdominal orchiopexies were performed. Laparoscopic orchiopexy was performed even more commonly in 2013 $(p=0.018)$ and $2014(p<0.001)$ than in 2012. Patients undergoing the laparoscopic approach were younger (mean $919.8 \pm 1123.8$ versus $1266.0 \pm 1381.5$ days, $p<0.001)$. The mean length of stay was shorter for laparoscopic patients $(0.17 \pm 1.2$ versus $0.48 \pm 4.4$ days, $p=0.035)$, however open surgeries were quicker ( $73.7 \pm 65.8$ versus $85.9 \pm 50.5$ minutes, $p<0.001)$. While the complication rate was low for both approaches, they were more than twice as likely to occur with the open approach ( $p=0.03$ ). There was no statistical difference in reoperation rate ( $0.3 \%$ laparoscopic versus $0.6 \%$ open) or readmission rate ( $1.2 \%$ laparoscopic versus $1.8 \%$ open).
\end{abstract}

Conclusions: Although the open approach to abdominal orchiopexy takes less time to perform, the length of stay is longer. Immediate post-operative complications occur rarely, but are more common with the open approach.

\section{Introduction}

Very common, undescended testes are encountered in around $1-4.5 \%$ of full term male infants [1]. Of those, around $25 \%$ are nonpalpable, with less than $60 \%$ of nonpalpable testes found within the abdomen at exploration [2]. Nonpalpable testis may become palpable under anesthesia. Of those which do not, laparoscopy can be both diagnostic, to confirm the presence of an abdominal testis, and therapeutic, when used to perform laparoscopic orchiopexy [3]. The 2014 update of the American Urological Association (AUA) "Evaluation and Treatment of Cryptorchidism: AUA Guideline" recommends either laparoscopic or open exploration or orchiopexy equally, as neither approach has been shown to be superior either in identifying nonpalpable testes or successfully bringing the testis to the scrotum [3].

For both the open and laparoscopic approaches, orchiopexy of the abdominal testis may be performed in either one stage, with or without division of the testicular vessels, or two stages, where the vessels are divided in the first stage and the testis brought to the scrotum around 6 months later, after presumably improved collateral blood flow from the vasal vessels [3]. Abolyosr randomized children to either open or laparoscopic orchiopexy after confirming there was an abdominal testis with diagnostic laparoscopy. He reported quicker operative times, return to normal eating, discharge from the hospital, and resumption of normal daily activities 
after laparoscopic orchiopexy. There was no difference in testis position or viability after one year of follow up [4].

Immediate post-operative complications are reported rarely for both approaches. A systematic review comparing staged and single-stage Fowler-Stephens orchiopexy found that complications were addressed by half of the 45 articles they reviewed. No complications were reported by the one study evaluating the single stage approach, while ileus, hematoma, and infection were the most commonly reported complications of the two stage approach. It is unclear whether the patients were undergoing open or laparoscopic orchiopexy, as the meta analysis included patents who underwent both [5]. Bladder injuries have been reported for the laparoscopic approach, however placement of a Foley catheter prior to incision can mitigate that risk [6].

As the AUA guidelines committee found that there is no benefit in terms of outcomes to recommend one approach over the other, we sought to determine if other operative factors may impact the decision. With improved visualization and smaller incisions, we hypothesized that the laparoscopic approach would be quicker, with fewer complications.

\section{Materials and methods}

After our institution confirmed that Institutional Review Board approval was not necessary because of the nature of the study, we performed a cohort study of pediatriac patients included in the 2012-2014 American College of Surgeons (ACS) National Surgical Quality Improvement Program (NSQIP) Pediatric data file. Partnering with the American Pediatric Surgery Association, the ACS started NSQIP Pediatric. The data set includes 94 data points from birth to age 18 across subspecialties from participating hospitals. The NSQIP Participant Use Data File is a HIPAA-compliant data file available to hospitals contributing data to NSQIP. The collected data focuses on the time of surgery to 30 days post-operative.

The NSQIP-Pediatric data file was queried for laparoscopic and open orchiopexies of abdominal testes (CPT codes 54650, 54692). Data points collated for this study included: age, ASA class, race, type of surgeon, length of stay, operative time, complications, immediate reoperation, and readmission. Our primary outcome was post-operative complications and rate. Our secondary outcomes were duration of surgery and length of stay.

Student T-tests and chi-square analyses were conducted to compare the children undergoing open versus laparoscopic orchiopexy for abdominal testes. Additionally the approaches were compared between the specialties that each performed a minimum of $1 \%$ of the total cases. A p value of $<0.05$ was considered statistically significant.

\section{Results}

Data was collected on 1,528 orchiopexies performed for abdominal testes. Of those, 1,039 were laparoscopic, while 489 were open. Pre-operative demographic data is presented in Table 1. Although the laparoscopic approach was more common in all three years of the study, the difference became more pronounced over time (Figure 1 ).

Ten different subspecialties performed the procedure. The top four services were pediatric urology $(80.9 \% ; 822$ laparoscopic, 414 open), pediatric surgery (11.6\%; 126 laparoscopic, 52 open), urology (5.4\%; 63 laparoscopic, 19 open), and general surgery (1.5\%; 23 laparoscopic, 0 open). The remaining 6 specialties performed less than $1 \%$ of the total cases: pediatric orthopedic surgery $(0.20 \% ; 2$ laparoscopic, 1 open), pediatric plastics $(0.13 \% ; 2$ laparoscopic, 0 open), cardiovascular-thoracic $(0.07 \%$; 0 laparoscopic, 1 open), otolaryngology - ENT (0.07\%; o laparoscopic, 1 open), pediatric otolaryngology - ENT (0.07\%; o laparoscopic, 1 open), and plastics (0.07\%; 1 laparoscopic, o open). Adult urology and general surgery were less likely to use an open approach than the pediatric subspecialties $(21.9 \%$ versus $32.3 \%, p=0.026)$. There was no difference in approach between pediatric urology and pediatric surgery $(p=0.294)$.

Post-operative clinical data are presented in Table 2. The open approach averaged about $15 \%$ shorter operative times $(\mathrm{p}<0.001)$. The vast majority of all patients went home on the day of surgery, however, those undergoing the open approach

\begin{tabular}{|c|c|c|c|}
\hline \multicolumn{1}{|l|}{ Table 1: Pre-Operative Demographic Data. } \\
\hline N & Laparoscopic & Open & p-Value \\
\hline Age (days, M \pm SD) & 1039 & 489 & \\
\hline & $926.1 \pm 1123.8$ & $1252.6 \pm 1381.5$ & $<0.001$ \\
\hline American or Alaskan Native & Race & & \\
\hline Asian & $0.6 \%$ & $0.6 \%$ & \\
\hline Black or African American & $3.3 \%$ & $3.7 \%$ & \multirow{2}{*}{0.355} \\
\hline Unknown & $16.1 \%$ & $18.8 \%$ & \\
\hline White & $17.8 \%$ & $14.1 \%$ & \\
\hline & $62.2 \%$ & $62.8 \%$ & \\
\hline ASA 1 & ASA Class* & & \\
\hline ASA 2 & 564 & 259 & \\
\hline ASA 3 & 341 & 169 & \multirow{2}{*}{0.906} \\
\hline ASA 4 & 124 & 58 & \\
\hline ASA & 6 & 2 & \\
\hline
\end{tabular}

*ASA class not reported for 5 patients.

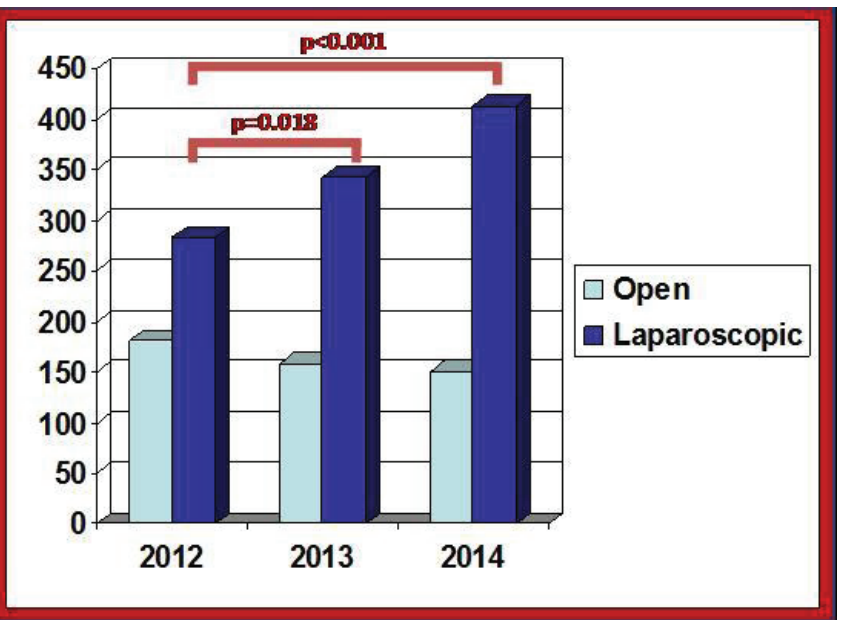

Figure 1: Change in Approach Over Time.

Although the laparoscopic approach was more commonly utilized at all time points during the study, the difference became more pronounced over time, with increased laparoscopy in both 2013 and 2014 when compared to 2012

Citation: Suson KD, Lakshmanan Y (2020) Immediate Post-Operative Course Following Open and Laparoscopic Orchiopexy of Abdominal Testes: Is There A Difference? Arch Urol Res 4(1): 017-021. DOI: https://dx.doi.org/10.17352/aur.000017 
stayed in the hospital nearly three times as long ( $\mathrm{p}=0.035)$. Complications (Table 3 ), rare in both groups, occurred more than twice as often following the open approach $(\mathrm{p}=0.03)$ The most commonly encountered open complications were pneumonia, superficial site infections, wound disruption, and sepsis. For the laparoscopic approach, superficial site infections, wound disruptions, and pneumonia occurred most commonly. There was no statistical difference in rates of postoperative ventilation ( $0.8 \%$ laparoscopic versus $0.4 \%$ open, $\mathrm{p}=$ $0.414)$, reoperation ( $0.3 \%$ laparoscopic versus $0.6 \%$ open, $\mathrm{p}=$ 0.344 ), or readmission (1.2\% laparoscopic versus $1.8 \%$ open, $\mathrm{p}=$ 0.403). No patients experienced organ infections, pulmonary embolism, progressive renal failure, acute renal injury, coma, stroke, nerve injury, venous thromboembolism, or death.

Table 2: Post-Operative Clinical Data.

\begin{tabular}{|c|c|c|c|}
\hline & Laparoscopic & Open & p-Value \\
\hline Operative Time (min, $\mathrm{M} \pm \mathrm{SD}$ ) & $85.9 \pm 50.5$ & $73.7 \pm 65.8$ & $<0.001$ \\
\hline Outpatient & $94.3 \%$ & $91.8 \%$ & 0.064 \\
\hline Length of Stay (days, $M \pm S D$ ) & $0.17 \pm 1.2$ & $0.48 \pm 4.4$ & 0.035 \\
\hline Complications & $1.4 \%$ & $3.3 \%$ & 0.03 \\
\hline Re-admission & $1.2 \%$ & $1.8 \%$ & 0.403 \\
\hline
\end{tabular}

Table 3: Post-Operative Complications.

\begin{tabular}{|c|c|c|}
\hline Complication & Laparoscopic, N (\%) & Open, N (\%) \\
\hline Superficial Incision Surgical Site Infection & $6(0.58 \%)$ & $2(0.41 \%)$ \\
\hline Deep Incision Surgical Site Infection & - & $1(0.20 \%)$ \\
\hline Wound Disruption & $3(0.29 \%)$ & $2(0.41 \%)$ \\
\hline Pneumonia & $3(0.29 \%)$ & $3(0.61 \%)$ \\
\hline Re-Intubation & - & $1(0.20 \%)$ \\
\hline Urinary Tract Infection & $2(0.19 \%)$ & $1(0.20 \%)$ \\
\hline Seizure & $1(0.01 \%)$ & $1(0.20 \%)$ \\
\hline Cardiac Arrect & - & $1(0.20 \%)$ \\
\hline Bleeding & - & $1(0.20 \%)$ \\
\hline Sepsis & - & $2(0.41 \%)$ \\
\hline Central Line Associated Blood Stream & - & $1(0.20 \%)$ \\
\hline Infection & & \\
\hline
\end{tabular}

\section{Discussion}

As hypothesized, the laparoscopic approach had a lower complication rate than the open approach. Additionally, patients left the hospital more quickly after laparoscopy. Contrary to our hypothesis, the open approach was quicker. However, both approaches are safe, with complication rates less than $1 \%$, and no difference in readmission or need for additional surgery. The usage of laparoscopy increased over the three years of the study period. Children in both the laparoscopic and open groups were older than one would expect. Not surprisingly, more than $90 \%$ of the surgeries were performed by pediatric subspecialists.

The American Urological Association recommends that primary care physicians refer babies with persistent undescended testes to a surgical subspecialist at 6 months of age, with surgery scheduled within the next year [3]. Others have suggested the ideal timing of orchiopexy should be between 6-12 months of age. This is after the period of spontenous descent, but offers the best chance of fertility preservation and optimal malignancy risk [7]. Additionally, surgery at a younger age may increase the likelihood of testicular artery preservation and successful surgery. Bagga, et al. found that old children have an increased distance between the internal ring and the mid-scrotum, and found this increase to be predictive of failed attempt at single stage, vessel preserving orchiopexy [8].

Children in our study were older than the recommended age for orchiopexy, both for the laparoscopic (mean $\sim 2.5$ years) and open (mean $~ 3.4$ years) approaches. Several studies have demonstrated children are undergoing surgery later than recommended. Yiee, et al. found that insurance status may be a factor, as patients with private insurance were more likely to undergo timely surgery than those without private insurance. Additionally, those with continuity of primary care were more likely to undergo timely surgery, especially if they are seen by pediatricians, as opposed to family or internal medicine [9]. Parental perception may also impact timing of orchiopexy. Chung, et al. found that younger, better educated parents with fewer children were more likely to agree to early orchiopexy [10].

Possible disadvantages to the laparoscopic approach include increased likelihood of performing a Fowler-Stephens orchiopexy. Ferro, et al. suggest this could be related to the difficulty in assessing if there is appropriate length [11]. However, when necessary, a staged Fowler-Stephens does seem preferable to a single stage surgery. There does not seem to be a difference in terms of success when comparing the laparoscopic and open approaches for either single stage or staged Fowler-Stephens orchiopexies [5]. Some centers, including Boston Children's Hospital, believe that a staged approach is preferable in the case of abdominal testes; their center is currently accruing patients prospectively to investigate that hypothesis (Orchidopexy Randomized Clinical Assessment (ORCA), clinicaltrials.gov identifier: NCT02235623) [12].

As demonstrated through our data, a significant portion of orchiopexies are still performed through an open inguinal approach. Some of these cases may represent testes thought to be intracanalicular, but later found to be intraabdominal. However, others represent a true preference of technique. Arena, et al. recently reported their experience with the open approach, all performed as a single stage, and found at follow up that no testes had atrophied and less than $5 \%$ were suprascrotal [13]. Pediatric urologists may also prefer an open second stage, if there is a concomitant indirect hernia. A study comparing inguinal to prescrotal orchiopexy for palpable testes found that $3.2 \%$ of patients in the prescrotal group developed post-operative inguinal hernias, one of which was incarcerated [14], thus the fear that untreated patent processes may progress. However, current literature suggests that leaving the processus vaginalis open at the time of laparoscopic orchiopexy does not seem to increase the risk of symptomatic hernias or hydroceles $[15,16]$. 
A randomized, prospective study was performed comparing the open and laparoscopic approach for "peeping" testes, when a testis is sliding in and out of the inguinal canal. They found that when the vessels are spared, there does not seem to be a difference in long term viability, intrascrotal position of the testis, or hernia, regardless of approach [17]. In this instance, a procedure that started laparoscopic may convert to open. One weakness of the study is our inability to determine if patients also underwent diagnostic laparoscopy, as that is not a separately billable code. There are also surgeons who may prefer to do a laparoscopic first stage and open second stage orchiopexy. In 2013, Casanova, et al. reported that when retrospectively assessing the longterm outcomes of staged Fowler-Stephens orchiopexy, those who underwent laparoscopic second stages were more likely to develop testicular atrophy ( $50 \%$ versus $20.4 \%, p=0.008$ ) [18]. Dave, et al. found that a long-looping vas deferens was associated with testicular atrophy in patients undergoing laparoscopic versus open staged Fowler-Stephens orchiopexy and suggested that it may be more difficult to manage laparoscopically. In their study, 61 patients underwent laparoscopic and 12 open staged orchiopexy, with a $20 \%$ atrophy rate in those undergoing laparoscopy and $0 \%$ in those undergoing an open second stage. No patients with looping vasa atrophied in the open group, while $83 \%$ atrophied in the laparoscopic group [19]. However, others have reported increased success with the laparoscopic approach. Stec, et al. reported in their retrospective review, the best success with 1-stage orchiopexy where the vessels were spared and when a laparoscopic approach was used, rather than open [20].

After weighing the conflicting studies, the AUA felt that there is no difference in success [3]. A systematic review of the literature found a paucity of good data comparing laparoscopic to open long term outcomes, however, from what was available, results seemed comparable [21]. Another review found that children undergoing laparoscopic orchiopexy left the hospital sooner, however there was no difference in operative time, return to feeding and normal activity, re-ascent, viability, success, or atrophy [10].

As a retrospective review of a national database, there are inherent weaknesses. More than concerns about coding errors, there is a lack of granularity to the data. For example, we are unable to say which patients underwent single stage and which underwent staged procedures. This could possibly mean that more of the open procedures were the second stage of an orchiopexy. As the NSQIP-Pediatric database is designed to provide 30 day perioperative outcomes, we are also unable to compare the failure and atrophy rates, or if patients required surgery outside of the 30 day window after a definitive procedure. However, despite these limitations, additional research is warranted; if both procedures truly are equally efficacious, but the laparoscopic approach is safer, then there would be an impetus for pediatric urologists to master this approach.

\section{Conclusions}

Although rare in both groups, the complication rate of open abdominal orchiopexy is twice that of the laparoscopic approach. The open approach did require less operating time, however, patients stayed in the hospital longer after the procedure. If outcomes are truly similar, this would provide evidence that the laparoscopic approach should be preferred. Children within the NSQIP-Pediatric database are undergoing orchiopexy one to two years after the AUA recommends. As children undergoing the open approach were older than those undergoing the laparoscopic approach, older ages at presentation may result in more open surgeries. Additional research into what drives the decision of approach and how to encourage our pediatric and family medicine colleagues to refer the children at a younger age are warranted.

\section{References}

1. Sijstermans K, Hack WW, Meijer RW, van der Voort-Doedens LM (2008) The frequency of undescended testis from birth to adulthood: a review. Int $\mathrm{J}$ Androl 31: 1. Link: https://bit.ly/2yabxrt

2. Smolko MJ, Kaplan GW, Brock WA (1983) Location and fate of the nonpalpable testis in children. J Urol 129: 1204-1206. Link: https://bit.ly/3ba1LUF

3. Kolon TF, Herndon CD, Baker LA, Baskin LS, Baxter CG, et al. (2014) American Urological Assocation. Evaluation and treatment of cryptorchidism: AUA guideline. J Urol 192: 337-345. Link: https://bit.ly/34Etier

4. Abolyosr A (2006) Laparoscopic versus open orchiopexy in the management of abdominal testis: a descriptive study. Int J Urol 13: 1421-1424. Link: https://bit.ly/2K2WwdJ

5. Elyas R, Guerra LA, Pike J, DeCarli C, Betolli M, et al. (2010) Is staging beneficial for Fowler-Stephens orchiopexy? A systematic review. J Urol 183: 2012-2018. Link: https://bit.ly/2XvlcSV

6. Hsieh MH, Bayne A, Cisek LJ, Jones EA, Roth DR (2009) Bladder injuries during laparoscopic orchiopexy: incidence and lessons learned. J Urol 182: 280-284. Link: https://bit.ly/3clE8IP

7. Chan E, Wayne C, Nasr A (2014) FRCSC for Canadian Association of Pediatric Surgeon Evidence-Based Resource. Ideal timing of orchiopexy: a systematic review. Pediatr Surg Int 30: 87-97. Link: https://bit.ly/3b9Qcgn

8. Bagga D, Teckchandani N, Kumar V, Grover SB, Yadav DK, et al. (2013) Predictive factors for successful vessel-intact laparoscopic orchiopexy for intra-abdominal testes. J Pediatr Urol 9: 453-457. Link: https://bit.ly/34zifTS

9. Yiee JH, Saigal CS, Lai J, Copp HL, Churchill BM, et al. (2012) Timing of orchiopexy in the United States: a quality-of-care indicator. Urology 80: 11211126. Link: https://bit.ly/34BXdEb

10. Guo J, Liang Z, Zhang H, Yang C, Pu J, et al. (2011) Laparoscopic versus open orchiopexy for non-palpable undescended testes in children: a systemic review and meta-analysis. Pediatr Surg Int 27: 943-952. Link: https://bit.ly/2V4MSOm

11. Ferro F, Lais A, Gonzalez-Serva L (1996) Benefits and afterthoughts of laparoscopy for the nonpalpable testis. J Urol 156: 795-798. Link: https://bit.ly/2RCx1nt

12. Orchidopexy Randomized Clinical Assessment (ORCA), clinical trials.gov. Link: https://bit.ly/2VwNACq

13. Arena S, Impellizzeri P, Perrone P, Scalfari G, Centorrino A, et al. (2017) Is inguinal orchidopexy still a current procedure in the treatment of intraabdominal testis in the era of laparoscopic surgery? J Pediatr Surg 52: 650-652. Link: https://bit.ly/2z13nC7

14. Al-Mandil M, Khoury AE, El-Hout Y, Kogon M, Dave S, et al. (2008) Potential complications with the prescrotal approach for the palpable undescended testis? A comparison of single prescrotal incision to the traditional inguinal approach. J Urol 180: 686-689. Link: https://bit.ly/2yacVKH

Citation: Suson KD, Lakshmanan Y (2020) Immediate Post-Operative Course Following Open and Laparoscopic Orchiopexy of Abdominal Testes: Is There A Difference? Arch Urol Res 4(1): 017-021. DOI: https://dx.doi.org/10.17352/aur.000017 
15. Narayanan SK, Puthenvariath JN, Somnath P, Mohanan A (2017) Does the internal inguinal ring need closure during laparoscopic orchiopexy with Prentiss manoeuvre? Int Urol Nephrol 49: 13-15. Link: https://bit.ly/2VrmEUJ

16. Khairi A, Shehata S, El-Kholi N (2013) Is it necessary to close the peritoneum over the deep inguinal ring during laparoscopic orchidopexy? J Pediatr Urol 9: 157-160. Link: https://bit.ly/3b6JGa0

17. Elderwy AA, Kurkar A, Abdel-Kader MS, Abolyosr A, Al-Hazmi H, et al. (2014) Laparoscopic versus open orchiopexy in the management of peeping testis: a multi-institutional prospective randomized study. J Pediatr Urol 10: 605-609. Link: https://bit.ly/34zje6w

18. Casanova NC, Johnson EK, Bowen DK, Kraft KH, Wan J, et al. (2013) Two-
Step Fowler-Stephens orchiopexy for intra-abdominal testes: a 28-year single institution experience. J Urol 190: 1371-1376. Link: https://bit.ly/3b7xZQl

19. Dave S, Manaboriboon N, Braga LH, Lorenzo AJ, Farhat WA, et al. (2009) Open versus laparoscopic staged Fowler-Stephens orchiopexy: impact of long loop vas. J Urol 182: 2435-2439. Link: https://bit.ly/2V5kNGi

20. Stec AA, Tanaka ST, Adams MC, Pope JC, Thomas JC, et al. (2009) Orchiopexy for intra-abdominal testes: factors predicting success. J Urol 182: 1917-1920. Link: https://bit.ly/2RCugm8

21. Wayne C, Chan E, Nasr A, Canadian Association of Paediatric Surgeons Evidence-Based Resource (2015) What is the ideal surgical approach for intraabdominal testes? A systematic review. Pediatr Surg Int 31: 327-328. Link: https://bit.ly/2RCQVPo
Discover a bigger Impact and Visibility of your article publication with

\section{Peertechz Publications}

\section{Highlights}

* Signatory publisher of ORCID

* Signatory Publisher of DORA (San Francisco Declaration on Research Assessment)

- Articles archived in worlds' renowned service providers such as Portico, CNKI, AGRIS, TDNet, Base (Bielefeld University Library), CrossRef, Scilit, J-Gate etc.

* Journals indexed in ICMJE, SHERPA/ROMEO, Google Scholar etc.

* OAI-PMH (Open Archives Initiative Protocol for Metadata Harvesting)

* Dedicated Editorial Board for every journal

* Accurate and rapid peer-review process

* Increased citations of published articles through promotions

* Reduced timeline for article publication

Submit your articles and experience a new surge in publication services

(https://www.peertechz.com/submission).

Peertechz journals wishes everlasting success in your every endeavours.

Copyright: @ 2020 Suson KD, et al. This is an open-access article distributed under the terms of the Creative Commons Attribution License, which permits unrestricted use distribution, and reproduction in any medium, provided the original author and source are credited.

Citation: Suson KD, Lakshmanan Y (2020) Immediate Post-Operative Course Following Open and Laparoscopic Orchiopexy of Abdominal Testes: Is There A Difference? Arch Urol Res 4(1): 017-021. DOl: https://dx.doi.org/10.17352/aur.000017 